\title{
Sheffield

\section{Making virtual reconstructions part of the visit: an exploratory study}

PETRELLI, Daniela <http://orcid.org/0000-0003-4103-3565>

Available from Sheffield Hallam University Research Archive (SHURA) at:

http://shura.shu.ac.uk/25143/

This document is the author deposited version. You are advised to consult the publisher's version if you wish to cite from it.

\section{Published version}

PETRELLI, Daniela (2019). Making virtual reconstructions part of the visit: an exploratory study. Digital Applications in Archaeology and Cultural Heritage, e00123.

\section{Copyright and re-use policy}

See http://shura.shu.ac.uk/information.html 


\title{
Making Virtual Reconstructions Part of the Visit: An Exploratory Study
}

\author{
Daniela Petrelli \\ Art \& Design Research Centre \\ Sheffield Hallam University \\ Cantor Building, 153 Arundel Street \\ S1 2NU Sheffield - UK \\ d.petrelli@shu.ac.uk
}

\begin{abstract}
The paper reports a qualitative study with the objective of obtaining a better understanding of the use of 3D reconstructions as part of a visit to a heritage site. The same content was displayed on two different devices: a tablet that provides an augmented reality (AR) overlapping the reconstructions in the real world and a headset that immerses the visitor in the past via a virtual reality (VR) experience. These two settings were evaluated in two different heritage contexts: a house museum, and a display-case museum. Visitors and museum professionals participated and used both devices. The results show that an AR setting is preferred when it is possible to compare the present day with the past while VR is preferred to contextualise exhibits, particularly when the original environment was monumental. Guidelines to reuse 3D reconstructions as part of the visit are provided on the bases of the questionnaires, observations, and discussions collected during the study.
\end{abstract}

\section{Introduction}

The production of high-quality, multimedia content for the purpose of communicating complex, historical information in the context of a museum visit is an expensive process. To begin with, it requires curatorial expertise (to find original sources of reliable, up-to-date information to be composed into a consistent narrative); then the information collected must be effectively communicated to an audience (from dry-facts to storytelling); and finally the rendering must be compelling enough to engage and sustain the interest of visitors that may not have any knowledge on the topic. Interactive architectural 3D virtual reconstructions are an example of such multimedia content that is expensive to produce, but that holds much potential for visitors' engagement particularly in light of emerging affordable virtual reality (VR) devices such as Sony PlayStation VR, or Oculus Rift. Once the curatorial work of selecting the sources and the content is done, the cost of producing the $3 \mathrm{D}$ virtual reconstruction is down to both the expertise needed to master the technology, and to the lengthy process of creating a virtual world that represents in detail the evidence in the original sources. Cost-cutting strategies such as the reuse of existing 3D models are unlikely to occur within the heritage context where rigorous and faithful reconstruction of each element in the scene is expected. It goes without saying, that if 3D virtual reconstructions could be used in multiple different settings such as online or on the exhibition floor, then the cost of production would be more justified, as there would be multiple uses for the same content.

VR is appealing to both the public and heritage organisations, but there is a limited understanding of how it can be effectively integrated as part of the visit. Indeed VR has been presented and managed as a special experience offered alongside traditional exhibitions, as stand-alone supervised installations (from the early experiments surveyed in (Pujol 2004) to the most recent installations (Tate Modern 2017) (Museo della Scienza 2018) (Schofield et al. 2018)) rather than as a tool used by the visitors in autonomy while they experience the museum or the heritage site at their own pace.

This paper is a step in this direction and aims to shed some light on how the device, the interactive content, and the surroundings affect the visiting experience. In other words, the focus of this work is on how 3D virtual reconstructions (content) taken around the heritage site (via a mobile device) change the experience of visiting the heritage site itself (surroundings). In the case study discussed, the high-quality content created for two commercial VR interactive games for two very different heritage sites is reused in an app that provides visitors with views of the 
heritage from the past while being in the actual relevant place. However, as discussed in the next section, when VR is viewed on a tablet instead of a headset, the experience is not that of immersion, but of seeing the VR content overlapping the reality surrounding the viewer and therefore making VR, from the viewer's point of view, closer to Augmented Reality (AR) than to VR as commonly understood.

As part of this inquiry, visitors and professionals used a tablet (for AR) and a headset (for VR) in a study aiming at understanding:

- if and how 3D content could improve the visiting experience;

- if and how a different device (a tablet vs. a headset) changes the experience, and

- what is the impact of the heritage setting;

- what visitors prefer and how professionals imagine this technology to be effectively implemented.

The paper is organised as follows: Augmented Reality and Virtual Reality in museums are reviewed in the next section followed by the discussion on the rationale for designing "Views from the Past" and its implementation; the evaluation in two different heritage settings is presented next followed by a discussion on the findings; guidelines and reflections conclude the paper.

\section{Virtual and Augmented Reality for Heritage and Museums}

Visual reconstruction is a unique way of engaging visitors with challenging heritage, such as archaeological sites where very little is left to see and experience. Panels with artists' impressions of how a certain place could have looked and how people lived there have been used for decades and many museums use scale models to illustrate complex buildings and cities or to show how a place has changed over time. With the advent of computer graphics, such reconstructions have been progressively substituted by digital and interactive means with the result that a plethora of augmented, mixed and virtual reality applications have been implemented (Kebele et al. 2018). Technical development offered the heritage sector new opportunities for: documentation (acquiring real data via, for example, photogrammetry); representation (3D reconstruction); and dissemination (via immersive devices or "in situ" augmented reality) (Addison 2000). The new forms of documentation and representation have been instrumental to creating new forms of dissemination and visitors' engagement with 3D reconstructions. Early experiments used large installations such as CAVE display to give groups of visitors an experience of the past (Gaitatzes et al. 2002, Stone \& 0jika 2000); more recently, headsets have offered visitors individual immersive experiences (Hornecker 2010, Jung et al. 2016, Schofield et al. 2018); and mobiles have put 3D reconstructions of places in visitors' pockets (Liestøl 2014). The content delivered in AR applications, instead, varies from displaying additional textual information in-situ in the early experiments (Areti et al. 2008) to adding layers of content in real time over reality as mobile devices became more powerful (Keil et al. 2013).

These examples show how digital technology and cultural heritage have gone hand-in-hand since the early 90s: cultural heritage has been seen as a suitable place to experiment with the emerging technology of the day, and the sector has been keen to experiment even with digital devices that later failed in the market (see (Petrelli \& O'Brien 2018) for an historical overview). The purpose of using the latest technology is to attract new visitors by offering unique experiences that, regrettably, wear out as the novelty becomes common and the audiences "are no-longer impressed with basic [virtual reality] walk-throughs" (Stone \& Ojika 2000) pushing developers to provide more interaction, participation, and content (Stone \& Ojika 2000). In an effort to give more meaning to the experience of 3D reconstructions, the scenes have been (re)used as background for 'gamified' heritage experiences (Kateros et al. 2015, Champion 2015) with the aim of fostering new forms of learning. Research, however, has mostly focussed on tools and processes for making serious games rather than understanding the players' own experience. Instead, the intersection between entertainment and historical sources has been exploited with much success by the games industry: popular titles such as 'Assassin's Creed' (Dow 2013) and 'Rome: Total War' (Lowe 2009) show that, despite the fact that those games do not pretend to be completely accurate, players actually value scholarly authenticity (Whitaker 2016). Therefore there are opportunities in combining highly accurate 3D reconstructions with some aspects of 
interactive entertainment for the purpose of making heritage more engaging. This, however, is still a long way off.

A recent survey of augmented, mixed and virtual reality (Kebele et al. 2018) has mapped applications with respect to their purpose (education, exhibition enhancement, exploration, reconstruction, and virtual museum), the technology (tracking systems, display, and user interface), and setting (indoor, outdoor, or both for AR; non-, semi-, full-immersive for VR). Interestingly, there seems to be a polarisation of a given technology toward a specific use: Augmented Reality (AR) overlaps virtual content to reality, it is delivered on mobile devices or tangible installations for the purpose of augmenting the visit of an exhibition or to support the exploration of a site; Virtual Reality (VR), instead, blocks the real-world view and has been used mostly to create virtual museums and support education exclusively indoors (Kebele et al. 2018). For example, some museums now offer immersive VR experiences such as visiting a Bronze Age village (Rae \& Edwards 2016), exploring the Natural Science Collection with David Attenborough (Pavid 2018)), or landing on Mars (Museo della Scienza 2018) as part of articulated educational programs that run as one-off special events. AR, instead, is seen as a more advanced form of audio-guide when it is used to provide layers of information, often for knowledgeable users wishing to deepen their understanding. This is the case studied by Jung et al. (2016): they looked at both VR and AR in the context of visiting a Tin Mine Museum - in VR visitors experience going down a mine shaft (now closed), whereas in AR visitors could access multimedia information in addition to the information printed on the panels. Such split between AR and VR seems to be led by the system technical potential, what each device displays best and how this fits with the intended visiting experience. In other words, each device is used to display different content (in Jung et al. (2016) to enrich the visit with a ride on the mineshaft with VR and to consume additional information in AR). My intent with this paper is very different: I aim to gain a better understanding of how VR and AR, delivering the same content but used in different cultural heritage contexts, change the visiting experience.

AR and VR, defined on the basis of user experience make explicit the relation between the person and the space: "whether one is expected to feel egocentrically immersed within one's world [VR] or whether is one to feel that one is exocentrically looking in on that world from outside [AR]" (Milgram et al. 1994). A further element of distinction is the substratum: "is the environment being observed principally real, with added computer generated enhancements? Or is the surrounding environment principally virtual, but augmented through the use of real [...] imaging data?" (Milgram et al. 1994). Virtual and real are mutually exclusive: a high sense of presence in VR requires a simultaneous low level of presence in the real world (Schuemie et al. 2001) and vice versa for $A R$, a high sense of real impedes the sense of presence in the virtual world. Interestingly, VR engenders presence even when the virtual space is unpopulated and no interaction is expected (Schuemie et al. 2001), making VR ideal for heritage reconstructions. These two elements, the viewer and the world, are the basis for the distinction made in this paper $^{1}$ :

- VR provides a subjective view, centred on the self, of a principally virtual surrounding environment;

- $\quad$ AR builds on a real environment augmented by computational elements as something to look at in an objective way

Following this definition and conversely from previous research (Kebele et al. 2018), this paper shifts the attention from the technology itself toward the ecosystem of using it in place as part of a normal visit. It looks at how a tablet and a headset implement AR and VR respectively, how such technologies contextualise the same 3D reconstructions in different ways, how each device affects the visitor's experience, and how different heritage sites could implement them.

\section{Looking at Historical Places via "Views from the Past"}

The motivation for this study lays in the acknowledgement that 3D reconstructions of the past can lead to very different experiences if consumed on a headset versus on a tablet. The first is an immersion in the past (VR); the latter invites a comparison with the present (AR). Which reaction these devices elicit, may be affected by the type of heritage (e.g. if the visitor is currently standing in the actual place vs. is standing elsewhere). This paper aims to shed some light on how 3D

\footnotetext{
${ }^{1}$ Milgram et al. (1994) go on defining a general framework for mixed reality, not relevant here.
} 
reconstructions affect a visit, if the form factor of the device has a role, and the impact of the surroundings on the visiting experience.

This section first describes the rationale for making 3D interactive reconstructions part of the visit and how the concept developed; it then describes the implementation for a tablet (AR) and a headset (VR).

\subsection{Rationale and Concept}

This study is part of a broader research project (REVEAL ${ }^{2}$ ) that explores the use of Environmental Narrative video game as a means to foster engagement with educational content in history and science in the context of a school class ${ }^{3}$ or as part of a museum visit. The Environmental Narrative game genre (Rouse 2010) is a contemporary innovation in gaming characterised by rich, high-fidelity environments which are often unpopulated, but scattered with evidence of human activity which relates to the overarching narrative ${ }^{4}$. This narrative is typically communicated through voice-overs or written artefacts that reveal the story in an intriguing, non-linear fashion that promotes 'cognitive curiosity' (Malone \& Lepper 1987). Environmental narrative naturally lends itself to experiential, discovery-based learning approaches (Harrington 2012) thus fitting well with the non-formal education proposed by museums (Falk and Dierking 2000).

The environmental narrative VR games created in REVEAL are based on existing heritage: the house museum of Dr Edward Jenner, the pioneer of the smallpox vaccination, and the Forum of Augustus in Rome. The games are intended to be used at home or in schools, but there is an opportunity to reuse part of their content to enrich the museum visit with digital reconstructions of the heritage itself, as it was lived in - i.e. including furniture and traces of human habitation (Fig. 1, top) - this a fundamental feature of an Environmental Narrative game.
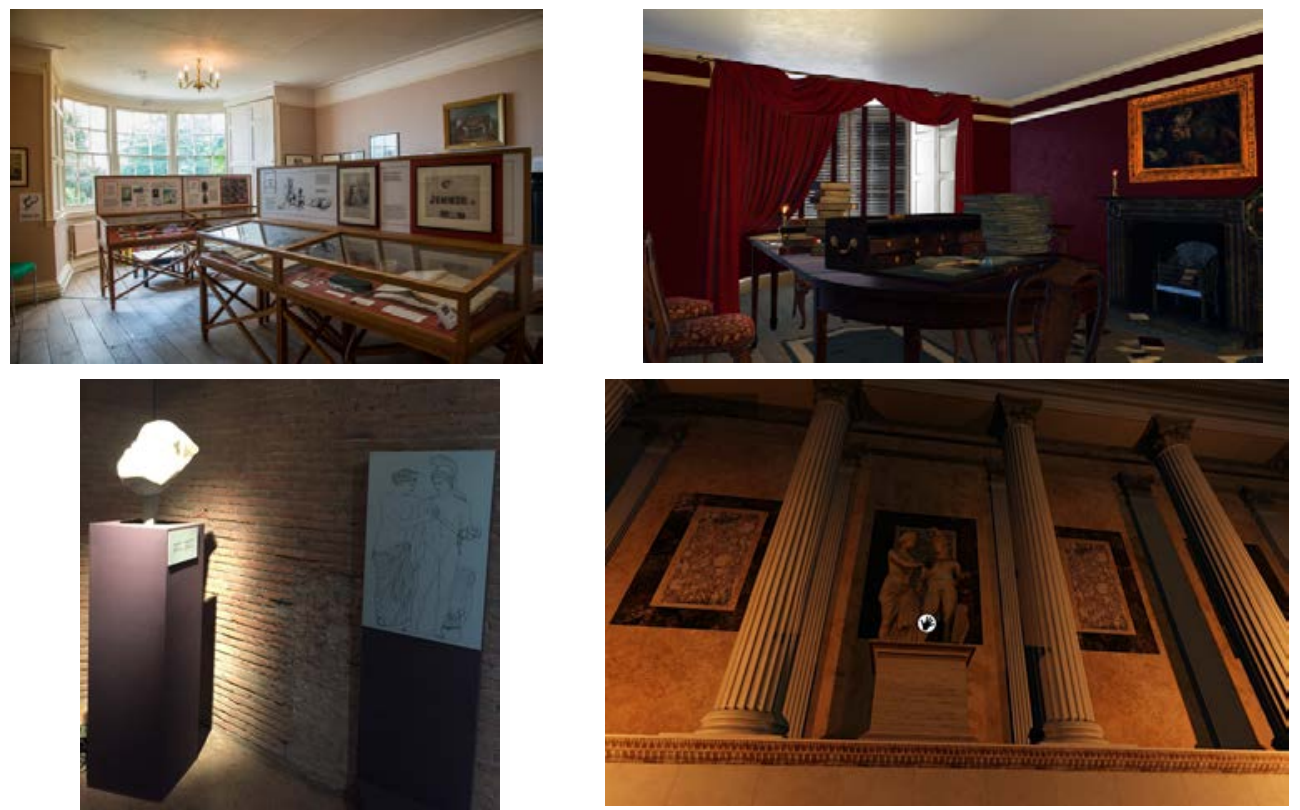

Figure 1. The settings: Dr Jenner's House Museum (top) as it is today and as it was in 1823; and (bottom) the fragment of the statue of Mars and Venus in the Trajan's Market museum and as reconstructed in context in the temple of Mars Ultor in the Forum of Augustus.

The concept View of the Past builds upon the rich and high-fidelity scenes in the games to engage the visitors' interest in exploring the place as if the inhabitants are only temporarily out: relevant $360^{\circ}$ scenes are extracted from the VR game and can be visually explored on a mobile device while in place.

\footnotetext{
2 REVEAL - Realising Education through Virtual Environments and Augmented Learning, https://revealvr.eu/ (accessed 7.2.2019).

${ }^{3}$ https://revealvr.eu/2019/03/11/reveal-in-the-classroom/ (accessed 7.2.2019).

${ }^{4}$ Examples of Environmental Narratives commercial games are "Dear Esther" (2012) and "Everybody's Gone to the Raptures" (2016), both by The Chinese Room.
} 
In the game, the player moves around the virtual environment via a handset device (Habgood at al. 2018), but visiting a museum is an embodied experience. The physical action of entering a space in the heritage site triggers the display of the correct scene, as the device is context-aware and reacts to where the visitor has taken it.

In the game ${ }^{5}$, the player interacts with objects by picking them up to observe them closely: picking up and manipulating an object plays snippets of narratives (as audio) and progresses the game. To maintain the access to narratives as part of the museum visit, some of the objects that in the VR game can be picked up became "hot spots" that play content when activated 6 .

The View of the Past concept requires a mobile platform, but can be implemented on both a headset or a tablet, each one providing a different experience (Fig. 2). The headset implements VR - it is immersive as it cuts out the surroundings and focus the senses on the virtual reconstruction, but it isolates the viewer from their visiting group; the result is that everyone in the group needs to use the headset to have a common background for a conversation.

The display of the reconstructed rooms on a tablet is, instead, an AR experience as the visitor is continuously aware of the reality and can continuously compare the present against the past. Moreover, the tablet fosters a shared experience among the visiting group, and may invite discussion and conversation more than the headset (as found by (Hornecker 2008) at a permanent installation in a natural science museum).

In other words, we can expect the VR experience via the headset to be visceral and subjective, while the AR experience on a tablet to be more cognitive and objective. Which one of the two forms would be preferred, if and how the heritage environment changes the experience and what the heritage experts think, is the matter of the study reported in this paper. The study then compares the two devices (headset vs. tablet) and two heritage settings (a house museum vs. archaeological pieces on display in a museum).
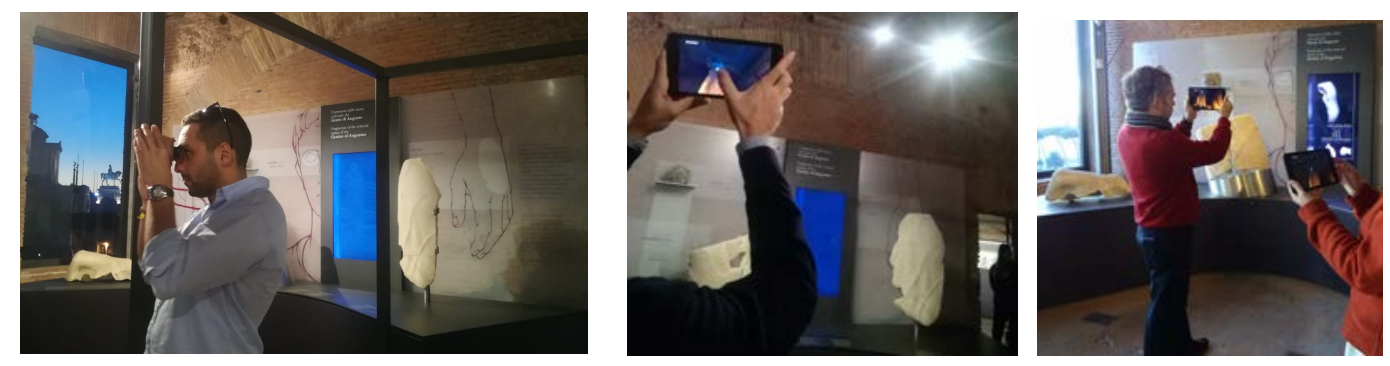

Figure 2. The VR experience (left) with the stereoscope and the AR experience with the tablet (centre and right)

\subsection{Implementation}

\subsubsection{Infrastructure and Headset Case, App and Interaction}

By being implemented on a mobile platform, Views from the Past can be taken around the heritage when visiting. Android was chosen because of its compatibility with Unity 3D that creates both a VR app for headset (e.g. Google Cardboard) and a 2D version for tablet use. Unity also supports mechanisms for selection within the scene displayed and therefore allowed to trigger audio content; also, it has been recently extended with libraries for detecting Bluetooth Beacons ${ }^{7}$, that is to say an event in Unity is triggered when a specific Beacon ID is detected. In this way, the selection of a 3D scene is done via the Beacon: when the visitor enters a room the app senses the Beacon ID and automatically changes the scene to the correct place. For Dr Jenner's garden, the Beacons were embedded within curious objects that matched the story, marked the interactive place and invited visitors to get closer: a pink hedgehog on the lawn; a bright-orange pineapple in the pinery; and hospital bags of blood hanging from a tree (Fig. 5 , left).

Effort was spent designing a form for the headset that conceals the phone (on which the VR app runs) and was sympathetic with the style at Dr Jenner's time: a Victorian stereoscope was the

\footnotetext{
5 Examples of the game being played can be seen at https://revealvr.eu/downloads/ (accessed 7.2.2019).

${ }^{6}$ It is impossible to replicate on a mobile device the closer observation of an object as picked up in the game.

${ }^{7}$ A Bluetooth Beacon is a small battery-powered hardware device that continuously transmits Bluetooth Low Energy (BLE) signals. The Bluetooth enabled smartphones are capable of scanning and detecting these signals.
} 
base of the design; the lenses holder taken from a second-hand theatre binocular was used to evoke a Steampunk device; a small 3D-printed trumpet conveys the sound from the phone toward the visitor's ear and a conductive button senses the clicks (Fig. 3, left). The Steampunk stereoscope was used for the Forum too as it was considered more playful and intriguing than a Google Cardboard ${ }^{8}$ even if the function of the two is the same.
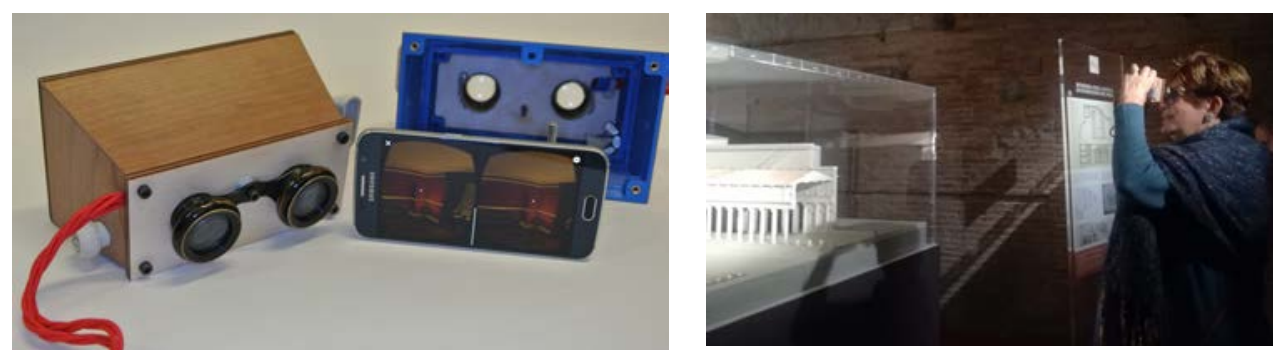

Figure 3. (left) The stereoscope with the phone in VR mode showing an interior of Dr Jenner's house. (right) The stereoscope in use at the Trajan's Market in front of the model of the Forum of Augustus. (stereoscope (c) Nick Dulake).

The games had been developed for Sony PSVR. As the PlayStation 4 console has significantly more processing power than the average mobile platform, a number of tests were carried out to find the optimal balance between device performance and visual quality for the intended experience. For each game, only the scenes relevant for the visit were included and for each of those only three interactive hotspots were chosen. The corresponding digital assets created for the PSVR game was imported into Unity with mixed success as the models resulted with no textures; textures were then applied to each model to create new prefabs that would work in Unity.

The second step was to recreate the same layout as in the PSVR game (developed in SONY PhyreEngine) for the mobile app in Unity. An early test of the phone performance with the exported assets from Unity showed the quality was not good enough for a smooth experience. The solution adopted takes advantage of the visitor's interaction as envisaged within the museum: the visitor stays still and turns on the spot to explore their surroundings via the headset or the tablet. For this purpose, a pre-rendered cube-map projection of the room or space would yield an almost identical result as no objects are so close to the viewer's as to require a change in depth perspective during the rotation. A reflection node was then used to make a cubemap, an output that can be repurposed for our needs, to pre-render the virtual environment. A limitation of this solution is that, if the visitor moves, the display does not resynchronise with the new position.

Besides changing the scene in response to the visitor's rotation, the display of the virtual environment on the tablet could be also controlled by touch: the view could be rotated using a finger, therefore, while the headset forced the visitors to rotate their body in order to "look around in the past", the tablet allowed also to "turn the environment" in order to look around. This function for the tablet allowed to overcome a known limitation: the display of the reconstructed space was not synchronised with the actual layout meaning that the visitor would have to turn their head to check the view from the past against the present.

In the VR experience, the interaction within the scene was created by overlapping a target area on the object that is in focus and therefore considered to be active. Interactivity in Unity is set up with a box collider and event triggers. This translated well to GoogleVR as it maps the interaction generated by button press (the button on top of the viewer): when the object in focus is selected, the corresponding audio plays. Thus, when using the headset, the visitor has to look around to discover which are the objects to which a story is attached and then click to play. This interaction could be seen as a way to explore the scene in depth while hunting for clues: a small "." displayed at the centre is a cursor to "scan" the scene and find where the content is located, shown when the "." becomes an "O" (Fig. 4, top), tapping on the button on the side of the stereoscope plays the audio.

The interaction with the 2D view (intended for the tablet) is different, as it is not possible to rely on the VR reticle to detect the focus (or hovering) and therefore a visual cue is needed to know

\footnotetext{
8 Google Cardboard is a VR viewer box made of cardboard designed to hold a mobile phone with a top button to implement user's selection (see https://vr.google.com/cardboard/ (accessed 7.2.2019).
} 
which of the objects are interactive. As in the game ${ }^{9}$, a little hand indicates the active objects: tapping the hand plays the audio content (Fig. 4, bottom).

While the game has many interactive objects in each scene, in the app only 3 for each scene were implemented as hotspots. This choice was motivated by the desire not to overwhelm visitors with the interactive but to leave them time to split their attention across several activities such as to look at historical objects on display or to discuss with visiting companions.
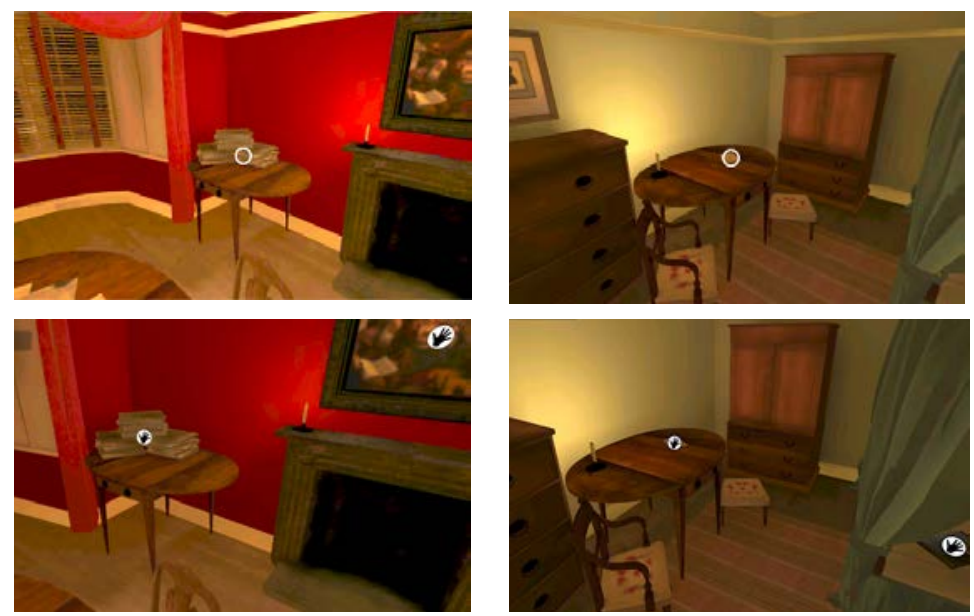

Figure 4. Content selection in Dr Jenner's house: top VR - the "o" shows only when the object is in focus; bottom AR - the hand marks a narrative. In VR only one content at the time is shown if looked at; in AR all contents in the scene is.

\subsubsection{Heritage Content}

The View of the Past concept is appealing to historical sites that substantially changed during the centuries, but for which it is known how the place looked. It was implemented for two different heritage sites: Dr Jenner's House Museum and Garden in the UK; and the Forum of Augustus in Rome. Both use exactly the same hardware setting and implement the same interaction; bespoke content was created for each app reusing the visuals and narratives created as part of the games $^{10}$ in collaboration with experts in the subject and using original and reliable sources.

\subsubsection{Dr Jenner's House Museum and Garden}

Up to his death in 1823, this house museum was the home of Dr Jenner, the physician who pioneered smallpox vaccine in 1796. It now hosts an exhibition about his scientific work. Photogrammetry was used to digitalize Dr Jenner's house as it is today while historical records were used to correct changes done over two centuries and to reconstruct the building as it was originally. The official inventory listed after the death of Dr Jenner was used to identify furniture and objects and to set the scene of the game. An iterative collaborative research process between curators and game designers took place to create the elements of the game, both the visual environment and the audio narrative. The result is an information rich, and visually compelling, VR game that tells the story of smallpox and vaccination from many points of view, such as science, society, daily life.

To play the game in full takes about 90 minutes, therefore, only part of the content was reused for the visiting experience that included both the house and the garden: seven cube-maps of the rooms open to the public and three fragments of narratives for each of the rooms where taken from the game, while new content was created for the outdoors as the game does not include the garden. Content for indoors ranged from how to best select a maid (one who already had smallpox), how patients could remain disfigured and how vaccination was ostracised.

Although they are all real facts, the stories for the outdoor sound surreal: Dr Jenner using human blood as fertiliser; dissecting hedgehogs to study hibernation; and cultivating pineapples to impress his guests. The humorous content inspired Pythonesque stop-motion animations and the animantions acted as visual anchor to the stories that the visitors would find in the garden (Fig. 5). In this way, the interaction would be the same indoors and outdoors: walking to a point, use

\footnotetext{
9 The game as played https://www.youtube.com/watch?v=Mz1oyMQsR8o (accessed 16.7.2019)

10 The two VR games are: "The Chantry" for Dr Jenner's House Museum and "A Night at the Forum" for the Forum of Augustus.
} 
the mobile device, watch and listen to a story. Overall the application for Dr Jenner's House Museum and Garden had ten points of interest, seven points indoors and three points outdoors, and twenty-one snippets of narratives from the game (indoors) and three short stories (outdoors).
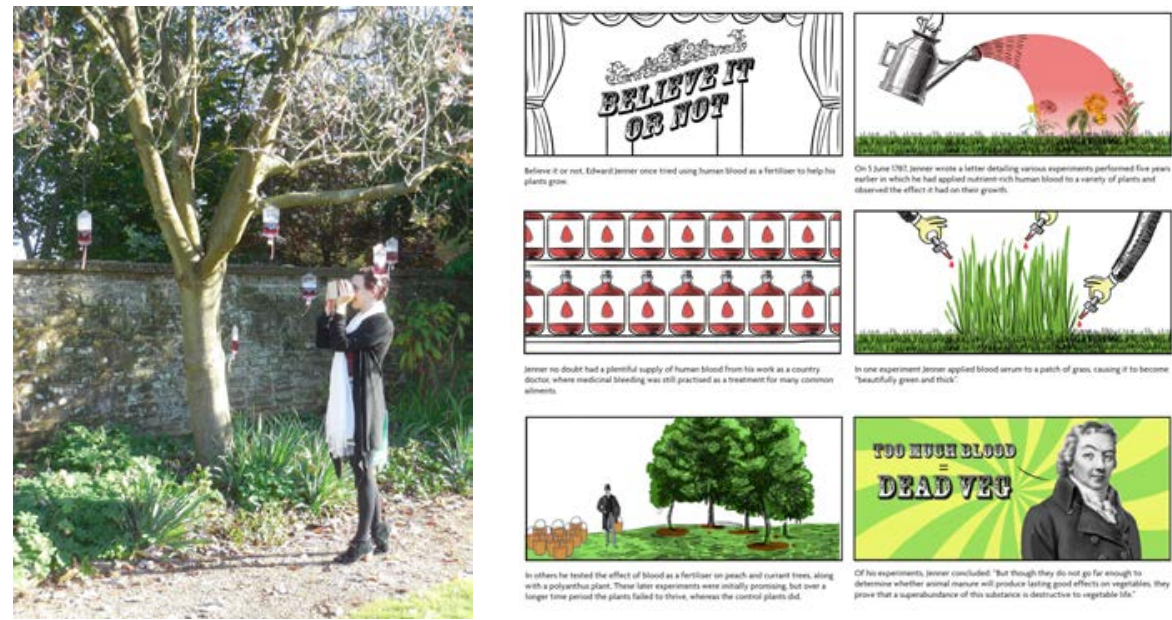

Figure 5. An example of the use of VR in the garden and the storyboard of Dr Jenner's experiments with human blood.

\subsubsection{The Forum of Augustus}

The Forum of Augustus was the second of the imperial forums in Rome and one of the most important buildings of the I century BCE. In the shape of a vast rectangle with columns and statues, the Forum included the temple of Mars Ultor (Mars the Avenger) and a hall with a colossal statue of Augustus; it was the place of several ceremonies, and provided an impressive space for legal proceedings. The starting point for the development of the VR game was a fullscale 3D model of the Forum of Augustus ${ }^{11}$ (Pescarin 2014) based on the most recent archaeological findings that have pushed archaeologists and technologists to reconsider the plan and to add two more exedras. The game is set at the time the forum was in use even though building work was still ongoing; therefore, one side of the forum, the one buried under a modern road, is unfinished in the game and a scaffolding gives the opportunity to explore Roman construction machinery as well as to see the forum from an elevated position ${ }^{12}$.

On the canvas of this stunning reconstruction, the narrative of the game weaves in historical facts about Augustus (told by Augustus himself), Roman rituals and practices such as how parties were summoned to court, and aspects of everyday life such as the attempt to move the judges to pity by dressing as beggars when coming to the tribunal (told by a narrator).

Fragments of statues and decorations from the Forum are now on display in the Museo dei Fori Imperiali at the Trajan's Market together with thousands of other remains from other sites. Five points of interest were identified within the Trajan's Market museum and three cube-maps were extracted from the game, meaning that the same cube-map was reused three times for different exhibits. Snippets from the narratives were selected to be placed in the scene; conversely from the Jenner's game where narratives are attached to single objects that we can expect the visitor to look at, here the narratives were positioned in places such as the steps of the temple that are not obviously points where people would look at making the discovery of the content more difficult (Fig. 8 shows the interaction in from of the Colossus of Augustus as implemented in the revised prototype developed taking into account the result of this evaluation).

\section{Evaluation}

Two evaluations were carried out, one for each game and heritage setting, and the same set of questions was used. In each evaluation, the same content was prepared for both devices, the tablet and the stereoscope; both would automatically show the $360^{\circ}$ View of the Past for any given place (marked by a Beacon) and would synchronise the display with the movement of the

\footnotetext{
11 The model was created by CNR-ITABC as part of the EU project V-MUST.

12 See the game at (work in progress) https://chrisredford.co.uk/ (accessed 17.7.2019)
} 
viewer. However, the starting point in the virtual world would not match the reality, e.g. facing the fireplace in Dr Jenner's drawing room would not centre the View of the Past on the fireplace. While it was possible to synchronise the position manually with the tablet, this was impossible with the stereoscope. Although not ideal, this was not considered a major issue as the comparison past-present was expected to occur with the tablet that could be manually aligned (AR), while the stereoscope was intended to create a sense of immersion in the past therefore cutting out the present (VR). However, as discussed below, this was not necessarily how the participants used each device.

The data collection was based on a questionnaire and an observer's note-book (reported in Appendix). The questionnaire asked to rate the device with respect to nine dimensions of tangible interaction (namely: pleasant, special, comfortable, interesting, surprising, useful, playful, easy to use, relaxing (Soranzo et al. 2018)), and how much participants agreed on seven statements on the experience (feeling back in time, present in the past, interested in the environment, engaged in the interaction, interested in the stories, feeling isolated, and able to share the experience). Two additional questions asked which was the preferred mode and why, and to explain why the other was disliked. The observer notes covered the behavioural aspects such as if they were in group or alone, where they stayed in the room, how they moved, how they used the device as part of their visit, if they shared the device and how.

\subsection{Jenner's House Museum and Garden \\ 4.1.1 Setup and Procedure}

A scene for each of the seven rooms accessible to the public and three fragments of narratives attached to objects were extracted from the game. In addition, three animations were created for the outdoors; these are humorous stories of Dr Jenner's other interests that complement and complete the indoors content on vaccination. The resulting app was deployed on a tablet, as a 2D display, and on a smartphone, as split-image VR to be used in the stereoscope.

The evaluation was carried out over a weekend when the museum run a special fund-rising event with PlayStation VR available for visitors to play the game. As they entered the museum, visitors were invited to take part in the study. No selection criterion was applied and who was invited depended on chance: who entered the museum when a researcher was available to take on a new group. About $40 \%$ of those approached accepted and were asked to use one of the two devices first on the ground floor, fill a section of the questionnaire, then swap for the other device to visit the first floor and the garden and complete the questionnaire with both their opinion on the second device and the comparison of the two. A researcher followed the participants and observed them interacting with the device and within the group taking noted on their behaviour. When on the first floor, participants had the opportunity to use The Chantry videogame on Sony PlayStation VR as part of their visit; however, their use of the PlayStation is not part of this study.

Those visitors who declined the invitation to take part motivated their response as: lack of time, no interest in technology, technology being felt as intrusive of the visit, and somewhat trivialising the content. This last motivation was put forward by those visitors that Bond \& Falk (2013) call 'respectful pilgrims' and 'community seekers' whose purpose for the visit is a personal connection with the place or the meaning it represents. For example, a couple with a 'historic house' membership motivated their choice not to take part by saying that technology does not belong in a historic house (community seeker). Another example was a family of 4, a young woman with her parents and her boyfriend: they visited because she had just started a university degree in Public Health and visiting Dr Jenner's house was part of her acknowledgement of the importance of his work for public health (respectful pilgrim). Her choice affected the family visit as the boyfriend, who decided to take part, was somehow marginalised while the mother, who looked very tempted to try, only used the devices very briefly as not to annoy her daughter and husband.

\subsubsection{Results}

Of all visitors approached, 20 took part: 5 were solo visitors (S1-S5); a group of 3 friends (volunteers in the museum) (G3); a family of 2 (G2); a family of 6 all taking part (representing 3 generations) (G6); and the above-mentioned family of 4 where only two members engaged with the study (G4). All were observed while visiting and 12 participants filled in the questionnaire: the 3 friends filled in 2 questionnaires; the family of 6 filled in 3 by generation (one for the 
grandparents, one for the parents and one for the daughters); in the family of 4 only the young man participated in full and filled in the questionnaire.

Overall the tablet (65\%) was preferred over the stereoscope (35\%). Motivations were: ease of use, awareness of the surroundings and other visitors (walking into people was a worry with the stereoscope); easier sharing. Observations clearly showed participants were interested in comparing how the rooms were at Dr Jenner's time vs. today: with the tablet, they manually synchronised the views on the screen with the space before turning on the spot with the tablet held high or slowly shifting the $360^{\circ}$ reconstruction with the finger. Observations showed that it was not easy for participants to position the view on the tablet the way they wanted as the screen was very sensitive and the scene fast-moving under touch; nevertheless, the preference was still on the tablet showing the interest for comparing today and the past overcame any usability issues they might have had. Only a few participants used their fingers to move the display of the room instead of turning on the spot: they seemed to use the tablet as a "delivery device" rather than as a tool to compare past and present.

With the stereoscope two behaviours were observed: participants who preferred the tablet continued to put the visor on and off thus comparing the room today and in the past; as the view and the room were not aligned, participants were often confused and frustrated as they had to reorient themselves every time. Those who preferred the stereoscope instead seemed to enjoy the immersive experience: they held the headset up while turning on the spot to take in the full room as it was about 200 years ago (as opposed to compare it with today). We also observed a few participants with the stereoscope making a few steps in front in an attempt to get closer to whatever was displayed to get a better view: this did not have any effect on the display as the room was a cube-map and not a dynamic model.

Sharing among the groups occurred with both the tablet and the stereoscope in the same way: even if the tablet could be looked at by more than one person at the same time thus sharing the experience, visitors tended to pass the device around for everyone to try it individually. This resulted in the tablet and stereoscope being used in the same way. The exception was G2 that shared the tablet and swapped the stereoscope possibly indicating that two people is the limit for comfortable sharing.

G6 was the only group that included elderly. As the group was large, they had both devices at the same time and this influenced their behaviour: while at the beginning all members used both devices, after a while each member used the one they preferred the most. For example, the grandmother preferred the stereoscope as the brightness on the tablet was too low for her to see while the mother preferred the tablet. Although both devices were used throughout the visit, the interest on the devices displayed by G6 decreased over time meaning they spent less time on the devices possibly because the novelty was wearing out. By the end of the visit each one of them were using only their preferred device. While the device was passed around much, the conversation was sparked by the exhibition and not by the reconstruction.

The content available was played in both conditions by all participants. Interestingly, comments on the intrusiveness of the audio were only voiced for the tablet as the directional audio of the stereoscope made it more discreet. While all participants clearly enjoyed the stories in the garden praising their humour and how informative they were, the content indoors (taken from the videogame) was criticised. While a fragmented narrative engages the player in long gaming sessions, when used as part of the onsite experience it becomes confusing, possibly demanding too much attention to reconstruct its meaning in short interaction. Participants also commented about the difference between the exhibition, focussed on vaccination, and the experience of looking back; they found the two were at odds with each other and tended to separate the two aspects of the visit, to observe the cases first then use the device after or vice versa. The museum volunteers (G3) suggested one should visit the museum in full first (requiring about one hour), then pick up the devices to explore the house as it was and last to use the VR game to go in depth into Jenner's story.

The dynamic of G4 showed the importance of the social context. Only the young man engaged with the devices in full, the mother was clearly interested and tried it twice when the husband was not in the room. The young man attempted, unsuccessfully, to share his experience with the young woman who was instead discussing the exhibition with her father. The father was very 
critical remarking: "children would like it" - and leaving the room when the audio played. The young man then reduced the use of the device in order to stay with the group.

The questionnaire asked participants to scoring each device respect to nine dimensions. Figure 6 shows participants' preferences grouped by device; a lower score indicates disagreement, a higher score indicates agreement with the centre being neutral. It is important to underline how the tables in Fig. 6 and Fig. 7 do not carry any statistical significance as the number of participants is too small; their value lays in the comparison across the devices. The charts show that those who preferred the stereoscope did so despite acknowledging it was not comfortable to use (the misalignment between the room and its virtual reconstruction discussed above) and it was more difficult to find and play the stories; these participants clearly valued the sense of immersion much more and show a stronger polarisation of opinions than those participants who preferred the tablet who acknowledged the stereoscope provides a stronger immersion in the past. The score for surprising and playful were expected to be higher for the stereoscope than the tablet: as the participants had the opportunity to play the VR game during their visit, we believe this lower score is due to having experienced VR (and indeed a better one) just before filling in the questionnaire. Although it is impossible to tell for sure, we could consider that, in a situation were no VR game is available, the stereoscope would have scored a higher value for playful and surprising.

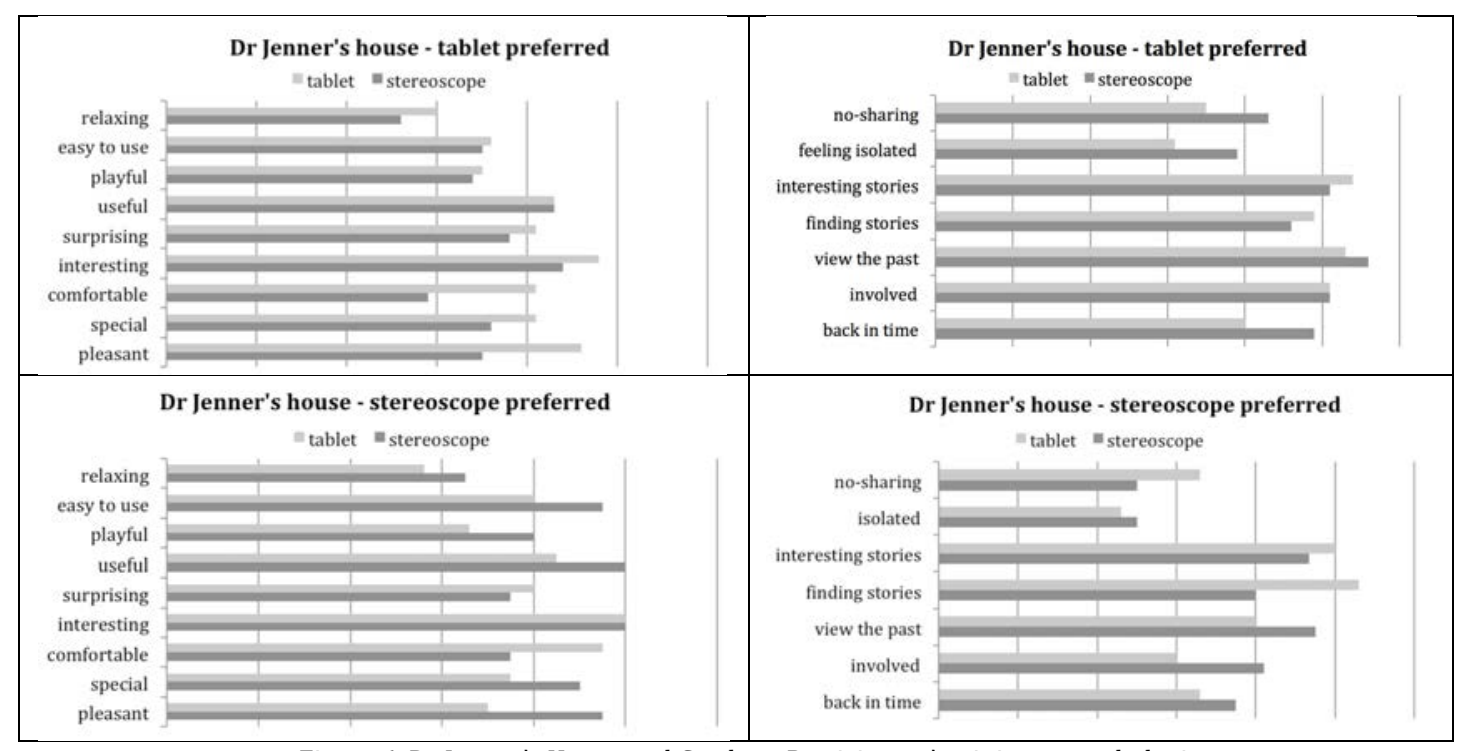

Figure 6. Dr Jenner's House and Garden - Participants' opinion on each device.

\subsection{The Forum of Augustus at the Trajan's Market Museum}

\subsubsection{Setup and Procedure}

Five scenes were extracted from the game 'A Night at the Forum'; they were the context of exhibits on display at the Trajan's Market Museum. In other words, the scene showed where the exhibit on display in the museum was located originally. As for Dr Jenner's House Museum, snippets of narrative relevant for the specific exhibit were selected from the game and no extra content was created. The evaluation within the museum allowed us to study different settings with respect to Dr Jenner's House, one in which the exhibit on display is contextualised in its original place via the virtual reconstruction.

Overall 11 participants took part in this evaluation, all were cultural heritage professionals familiar with the museum and connected with the institution to some degree. The involvement of museum professionals rather than the visitors was a necessity as on the day scheduled fro the evaluation the visitor flow was extremely low. This shift from visitors to professionals, although unplanned, enabled conversations on the potential and pitfalls of this technology, whilst also evaluating the devices. The result is a rich tapestry of information that goes beyond the preference for the tablet or the stereoscope and extends to a possible actual deployment and the integration of the devices in the management of the museum and the visitor flow. Indeed, the museum layout is so different from Dr Jenner's house that a radically different perspective on the same experience emerged, as discussed in the next section. The visit was done in small groups of 
2 or 3 professionals that tried both devices and filled in the same questionnaire as was done at $\mathrm{Dr}$ Jenner's house. Participants were: museum guides, historians, archaeologists, and heritage communicators. During the visit, they also discussed among themselves in a kind of "walking focus group" that brought to the fore ideas, pitfalls, and opportunities.

\subsubsection{Results}

The data from this evaluation recorded the opposite to the Dr Jenner's House Museum, with $70 \%$ of the participants preferring the stereoscope against $30 \%$ who preferred the tablet. The motivations were: the feeling of immersion the stereoscope provided and the sense of proportion of the space respect to the human size; a better experience, more stimulating and engaging. This can be explained by the fact that the visitors are not surrounded by the heritage, as it is the case in Dr Jenner's house, and therefore it is only via VR that one can experience the heritage site. Besides the lower sense of immersion, the tablet was considered too common a device to strike a chord: museum professionals seek digital technology as a way to offer novel experiences to attract and engage new visitors and a tablet now represents the everyday, not the exceptional (Petrelli \& O'Brien 2018). Those who preferred the tablet consistently named the value of maintaining a sense of the present (Fig. 6, top right) (as opposed to be transported back in time), but they also acknowledged the playfulness and the special quality of the stereoscope (Fig. 7 , top left). In clear contrast to the participants in the evaluation at Dr Jenner's House Museum, they also rate the stereoscope 'easy to use': this is due to the fact that no alignment from past and present is possible in this setting as the exhibits are displayed in a museum so not in their original position within the Forum of Augustus. However, they said the display could be improved by showing the element of interest in-front, e.g. Augustus' colossus or Mars \& Venus. The participants who preferred the stereoscope, fully embraced it consistently preferring it to the tablet (Fig. 7, bottom).

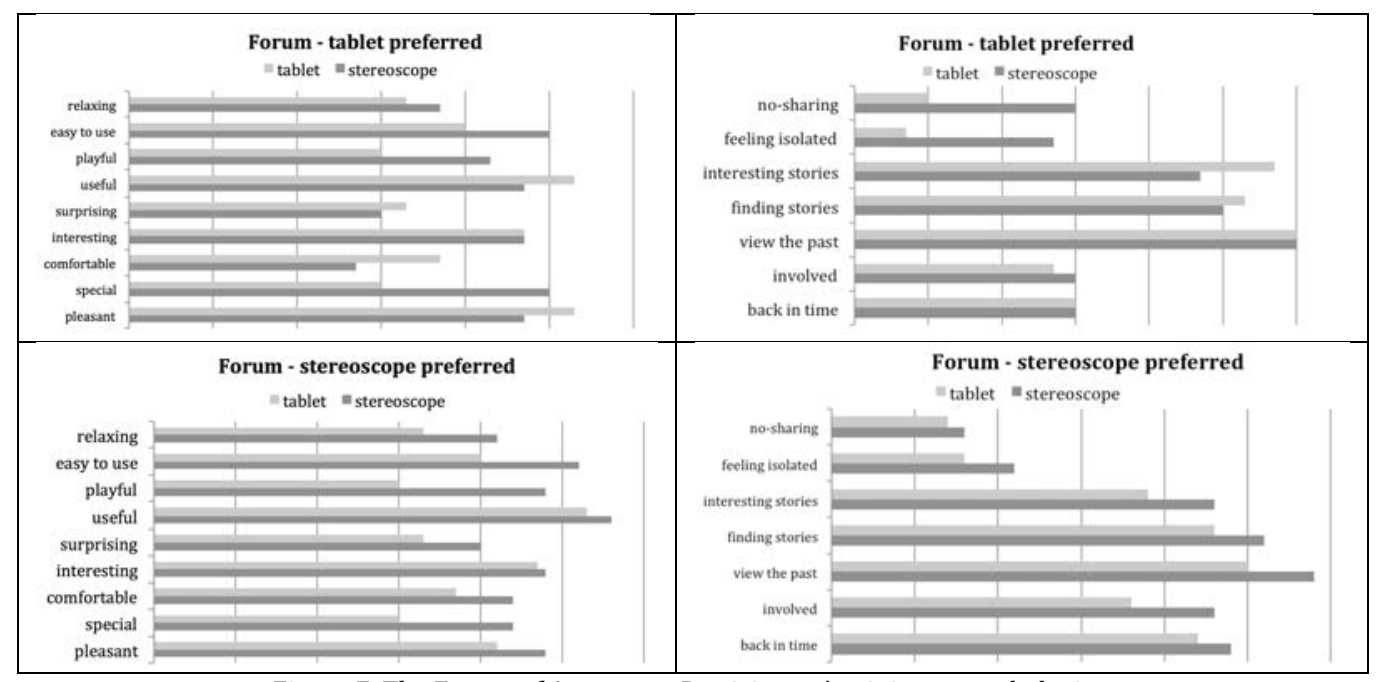

Figure 7. The Forum of Augustus - Participants' opinion on each device.

The museum professionals that participated in the evaluation consistently commented on the unsatisfactory quality of the commentary: they did not feel the content proposed (extracted from the game) was particularly suitable. They acknowledged the tone and the length was right: an audio-guide style, they said, is dated, and often the narratives are too lengthy and often boring. Instead of the fragments from the game, they suggested using engaging, short stories better connected with the exhibit, more emotional, curious and easy to relate to. A clear example of this was offered when we arrived at the fragment of the statue of Mars and Venus as in Fig. 1: the belligerent Mars, the God of war, can only be controlled by Venus who is represented as a calming presence in this sculpted pair with Venus resting her hand on Mars' torso. The historian who explained the pose said this was the only way in which Mars could stay (and be represented) within the city walls, always with Venus at his side, and put forward ideas on how to transform this fact into an engaging story, possibly made humorous by actors playing Venus as a caring wife telling Mars it was time to relax and that there was no need to get so angry. The need for content that is tuned to the exhibits was paired with the request for a visual representation, within the VR reconstruction, of the position of the fragments that were on 
display. This would provide the visitor with a clear indication of the original context of each piece on display. How to do this was discussed: the night scene - much appreciated by the participants - offers an opportunity to use spots of lights to indicate where the specific piece on display is located. However, this subtle method may not be so obvious to visitors and an icon, possibly interactive to trigger content, may be the best choice in terms of usability.

A further suggestion on how to improve the contextualisation of the objects on display was to create more and differing views that could surprise the visitors. For example, the view in the room of Victory's foot could transport the viewer precisely onto the Victory's position up on the temple roof: this would provide the viewer with the sense of how grandiose the Forum of Augustus was, and possibly, it would offer a glimpse of ancient Rome beyond the wall that surrounded the forum.

Much discussion occurred also around the 3D reconstruction, on what is known (e.g. the hall of the colossus of Augustus) and what is a reasoned guesswork (one end of the forum is still under one of Rome's main roads). Although caution was a major concern, all the professionals taking part in the study agreed that the driving force for these types of applications should be to give a sense of what an amazing place the Forum of Augustus must have been. They appreciated the stratagem for the side of the forum still unknown to be under construction and very much liked the night-time ambience with only the light of the moon and the fires in the braziers.

Finally, the professionals put forward ideas on the use of the devices by the visitors. They were concerned with visitors carrying the device around the museums: the Trajan's Market is a large complex of ruins that hosts exhibits about the Roman fora, not just Augustus', and requires about 3 hours to visit. To carry the device for the whole visit but to use it only sparsely was considered a nuisance; a further issue is the number of devices needed as in such a large space there can be easily 500 visitors at the same time. This means that the museum must have a very high number of devices to hand out, and that the visitors must carry them for a very long time, despite the fact that it can only be used at a few places. Therefore, a mobile device may not be the best choice and instead VR explorative points could be installed in some rooms as to provide an immersive experience without the burden of carrying it (see (Hornecker 2010) for a solution based on VR binoculars and large screens).

\section{Discussion and Guidelines}

This qualitative user-centred study aimed at unpacking the ecosystem of heritage, device, and content that is created when digital reconstructions are used to enhance a visit to a heritage site or a museum. The visitor's experience is very different from sitting in a VR booth as part of an educational package (e.g. Museo della Scienza 2018) or as a special attraction in an art gallery (e.g. Tate Modern 2017) or a museum exhibition (Schofield et al. 2018). Issues related to the context of use come to the fore, and change the meaning the reconstruction itself has - in terms of the appreciation of the heritage. This section reflects on the findings and suggests a set of guidelines for 3D reconstructions to become part of the digital augmentations offered to visitors.

The data collected at both Dr Jenner's House Museum and at the Trajan's Market consistently shows the value of reusing visual reconstructions as part of the visit. It was clear that the setting determines which device is more suitable: at Dr Jenner's house, where a direct comparison between the present and the past is possible, the tablet was chosen by participants as the best option; at the Trajan's Market the stereoscope was chosen as the one that truly gave a sense of immersion in the long-gone, awesome space of the Forum of Augustus. The different context is important: the sense of proportion at the Forum and the representation of the original context for the objects on display could only be achieved via VR on the headset while the past-present comparison is facilitated by the AR settings provided by the tablet. This attitude was shown by the participants' behaviour: they repeatedly shifted their attention from the device to the space at Dr Jenner's house while they spent time exploring the space of the Forum taking in the sensation of being present in a space whose size and splendour is unmatched to date. As such, which device should be favoured for experiencing 3D reconstructions during the visit depends on the heritage itself.

Guideline 1-3D reconstructions experienced in VR engender presence that, in turn, evokes the same emotions as a real experience (Schuemie et al. 2001). Therefore VR should be preferred when the heritage is in ruin or lost and is particularly effective when the space was (originally) 
imposing and grandiose. 3D reconstructions experienced in AR are instead ideal to compare the present day and the past, and foster a more cognitive approach to heritage.

Fundamental to an effective informal education via VR is the visual quality of the surroundings and freedom of exploration (Harrington 2012). Two VR commercial games developed at industry-standard have been the starting point for this research. The high-fidelity and photorealistic rendering clearly engaged the participants in a visual exploration of the virtual places. This result calls into question the choice of 'gamifying' VR and AR experiences of heritage via quiz (e.g., Liestøl 2014, Kateros et al. 2015) as appreciation can be achieved by an accurate reconstruction of the past and engaging stories, rather than by adding activities. A further element of reflection is that the setting has been intentionally designed to be unpopulated (a home as left by its last inhabitant, a Roman forum at night) for two reasons: the attention should be on the place and the surrounding objects and characters would be a distraction; to produce photorealistic characters in the game would have been impossible within the given means. Guideline 2: the most of the work should be devoted to creating an outstanding visual reconstruction (rather than adding characters or additional layers such as a quiz), as this is the single most important element of the experience.

Whilst the visual elements from the VR game translated well onto the mobile, the fragmented narratives, so effective in environmental narrative games, resulted as being too disconnected to the heritage. Indeed, consistently, in both evaluations, participants suggested ad-hoc content should be prepared such as self-contained mini-stories to which people can relate, humour and drama were genres suggested. Approaches to audio narratives for lost heritage that build on dissonant and ludic histories 'from below', e.g. the pickpocket or the juggler, have proved very effective in bringing together historical rigour and entertainment (Poole 2018) whilst the reuse of content intended for different devices may diminish the experience (e.g. text from panels, video clips from screens, and narratives from audio-guides were less than ideal on smart glasses (Mason 2016, Archeomatica 2016)). The crafting of new narratives that fit the new use is key to a sustained enjoyment of the experience, particularly when the visual reconstruction for a place is a repetition of or similar to what has been seen before: to find new stories gives purpose to the visual exploration of the 3D reconstruction. At Dr Jenner's House Museum, the novelty of looking at a $3 \mathrm{D}$ reconstructions wore out as rooms became, in the end, very similar to each other (the three bedrooms on the first floor): engaging stories would have kept visitors' interest alight. Distinct and self-contained stories are an obvious and simple approach but more articulated forms of interactive storytelling could be implemented where the story evolves as the visit progresses. Other forms of evocative audio content could be used such as soundscapes (Schofield et al. 2018), poetry and songs (Petrelli 2019).

Guideline 3: the outstanding visual reconstruction should be paired with equally accurately crafted, and compelling, storytelling that fits the heritage and the self-exploratory experience. Nothing else is needed to make the experience memorable.

Visiting a heritage site or a museum is an embodied experience; visitors' movements can be exploited to reduce the interaction to a minimum: Beacons automatically set the scene to display, and a single action by the visitor starts the story. In fact, there is no evidence that the sense of presence augments with increased actions (Schuemie et al. 2001). Moreover, as visitor's movements within the place are not recorded by the devices and the scene does not change, VRinduced motion sickness is avoided.

Guideline 4: VR or AR as part of the visit should be designed for minimal interaction and to leave ample space for the enjoyment of the real setting.

The headset usability affected the experience at the two heritage settings in a very different way. The fact that the VR was not automatically aligned to reality was a big issue at Dr Jenner's House Museum and the participants were clearly disorientated and frustrated, often missing to recognize they were looking at the same room as it was in the past. At the Trajan's Market, the VR contextualised the object on display in its original setting; here the misalignment was inconvenient, but not an issue, as the participants turned on the spot to find the focus of the scene and explored the place from there.

Guideline 5: the interaction should be tested in place in a naturalistic way, observed usability issues should be removed or at least contained. 
A point of distinction between the two heritage settings was the logistics. Dr Jenner's House Museum and Garden is a small place, and it is possible to imagine a progression of visiting depth: first the exhibition about the vaccination, then a second visit using the tablet to see how the house was and to discover who Dr Jenner was, and finally the VR game for a full and extended experience. This approach of multiple tours in the same visit cannot be proposed at the Trajan's Market, as its size of 3000 square meters prevents any possible return to the starting point for a second visit. An option could be to install the stereoscopes as in-place-binoculars on a rotating pole, that is to say to fix an 'observation point' to the floor in the rooms where a 'view of the past' is available: what the binoculars show can then be projected on the wall for the other visitors to see.

Guideline 6: VR and AR can be part of the visiting experience but the design must be bespoke for the heritage site, so as to implement a manageable solution, e.g. a few devices locked to specific points of interest may be enough to create a memorable experience. What is important is a compelling audio-visual content and ease of use.
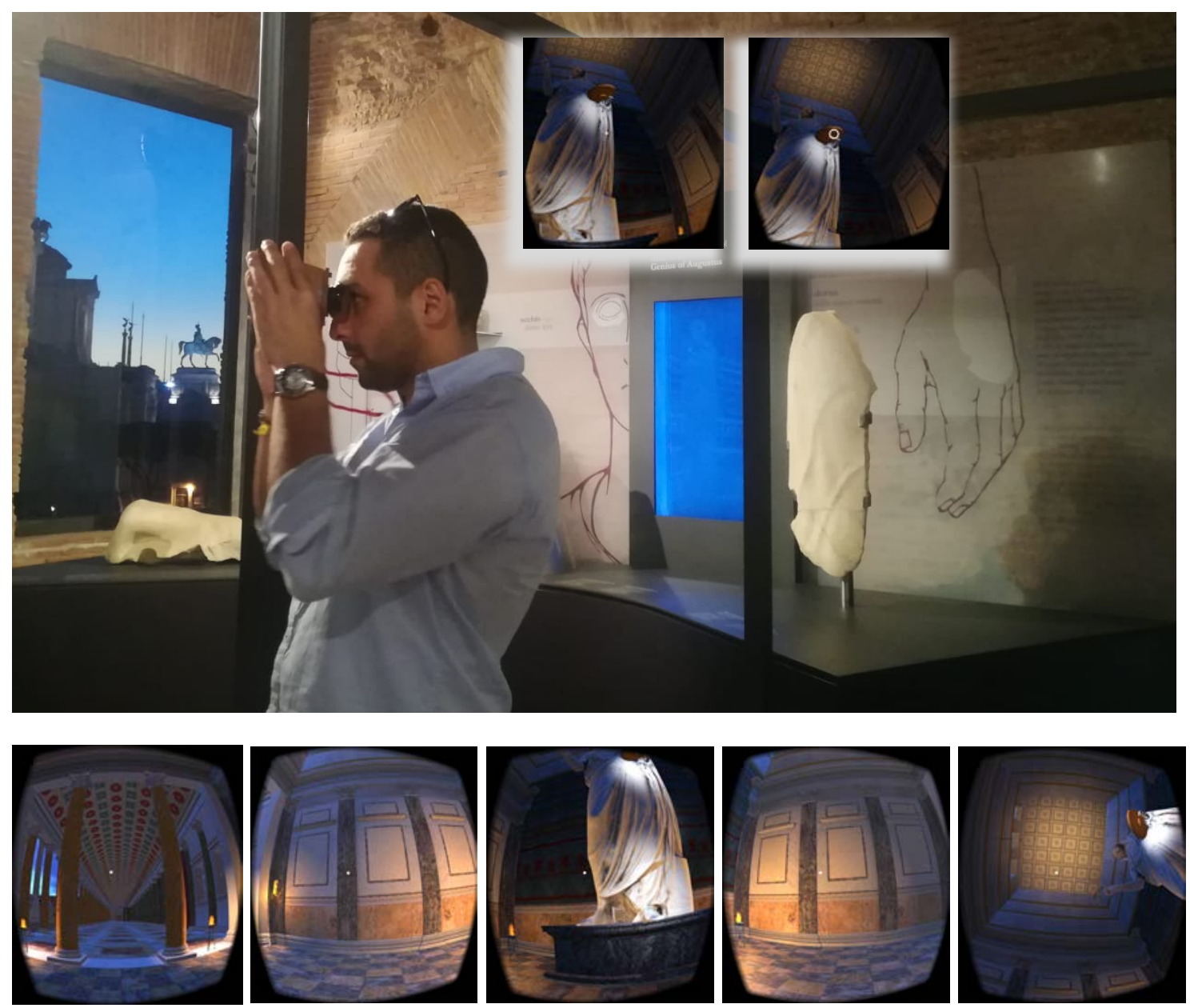

Figure 8. The interaction with the Stereoscope in front of the fragment of the Colussus of Augustus. The image distortion is due to VR deformation. The bottom line shows the cube-map (four sides and the ceiling). In two inserts in the large image above shows what the visitor is looking at: on the left the "." shows the visitor is exploring the scene; on the right the " $\mathrm{o}$ " shows an audio narrative has been triggered. The two spots of light on the statue show content hot-spot.

\section{Conclusions}

New technology brings new opportunities and with it the need for a good understanding of how the experience changes and what content is most appropriate for each heritage setting. This paper explored the opportunities and pitfalls related to creating VR and AR experiences for visitors to take around the heritage site in order to self-explore the past. The effort and costs needed to develop interactive 3D reconstructions could be exploited in multiple ways, if an experience of the visit is based on the same content. The reuse and repurpose of the same 
content allows the heritage institution to reach a larger audience: in this study, regular visitors were reached, beyond those who buy VR games to play at home and the students who experiences the game in the class when used as a teaching tool ${ }^{13}$. In this study, the content is used twice, once as part of the VR game and also as part of the visit. Further cases of content-reuse could be imagined, for example, to augment publications by allowing the reader to explore the place as it was, or as a component of a digital strategy for online content. With every reuse, the high cost associated with the production of high-quality content becomes more justifiable, and could open up new revenue streams for the heritage site: in the perspective of VR becoming mainstream, a positive experience in the museum could induce some visitors to purchase the game, thus providing the museum with an additional income.

Clearly the data collected is small and should be considered only as an exploration of the effect of taking 3D reconstructions to a place. The findings are encouraging: they show such instruments have value. However, our attempt for minimal-effort creation of these interactive exhibits by reusing content from the game proved suboptimal. Indeed, the content that was really appreciated was the animated mini-stories purposefully created for the place. Therefore, while the $3 \mathrm{D}$ reconstruction enriches the visit, the content must be carefully crafted as to keep the engagement high.

This could be limited to the creation of ambient sounds that reflects the historical period of that place (e.g. spoken ancient English and ancient Norwegian for the VR reconstructed Viking village (Schofield et al. 2018)), or to more emotional personal narratives recounting events that happened in place (e.g. excerpts from personal diaries, letters, and even poetry played in the trenches and fortified camp of WWI (Marshall et al. 2016)). The findings, although limited by the small number of participants, show there is no need for more complex interaction to engage visitors. Quite to the contrary, the device must be very simple to use; ideally there shouldn't be any need to learn how to use it. As a response to the issues found in this study, an improved version of the prototype was implemented with two important changes: the hotspots with the content are made more prominent in the $3 \mathrm{D}$ reconstruction by a spot of light; as the visitor looks at it, the audio plays (Fig. 8 shows the interaction with the final prototype). Although no formal evaluation has been conducted, those who tried this new version found it straightforward to use: the observations of their behaviour showed that it was natural for them to look directly at the spots of light that automatically triggered the content removing the need to find the content and to click the button to play it.

In essence this exploratory study opens up new opportunities for further research. First that the heritage environment, the device, and the content are all intertwined and each one affects the other: a comparison past-today calls for AR while an immersion in what is lost fits VR best. Therefore, environment, device, and content should be considered simultaneously when designing a visiting experience. More research is needed to better understand how the three combine. For example, would the comparative power of AR be more appreciated than VR in an archaeological site or is the emotional immersive experience of VR dominant when very little is left to see?

Similarly, the different purposes of VR (immersion) and AR (comparison) may indicate a preference for different content styles. For example personal accounts could be a better fit for VR, whilst a narrative that is a "guided observation" could amplify the comparative function of AR.

Secondly, this study used 3D reconstructions while AR in heritage often overlaps to reality the reconstruction of some elements rather than the full scene. This clearly changes the content and therefore, further research is needed to see if this has an impact.

While this study clearly shows that both visitors and professionals see value in these types of applications, some practical issues need addressing before they can be used every day. For example, the Beacons were very effective in automatically changing the scene with respect to where the visitors were standing, however, they could interfere if the field of two Beacons overlaps. At Dr Jenner's House Museum, for example, Beacons on different floors could interfere if the visitor was (geometrically) closer to the Beacon in the other room (e.g. immediately above) than to the one in the same room (e.g. across the room). Therefore, the visiting experience should be designed taking such restrictions in mind. Signposts could be used (e.g. a sign for the floor to

13 A VR-supported lesson https://www.youtube.com/watch?v=1oTKhdT3xWU\&t=47s (accessed 17.7.2019) 
show where to stay was designed for this study); this will also help with the synchronous overlapping of the 3D reconstruction with the reality. Other practical issues relate to powering the device as the 3D scenes quickly consume the battery and may need frequent recharging. The stereoscope also poses the challenge of overheating (a problem found also by Schofield et al. (2018) ). Our solution was to create more openings in the case (as Schofield et al. (2018) did too), but a more radical solution would further optimise the rendering of the scene for mobile use. This opens up a more technical path to explore to make such applications easier to use for visitors and more manageable by staff.

\section{Acknowledgements}

I would like to thank my talented colleagues and associates for making their work available for my study, specifically: Jake Habgood and David Wilson at Steel Minions Studio at Sheffield Hallam University for 'The Chantry' videogame; the many colleagues at Viatron and CNR ITABC for 'A Night at the Forum' videogame; Nick Dulake for the design and production of the stereoscope; Chris Redford (https://chrisredford.co.uk/) for his drawings for Dr. Jenner's garden animations; Elliott Hill for porting the content from the PSVR to Unity and for implementing the apps. I am also grateful to the Director of the Trajan Market, Dr Lucrezia Ungaro, for making the museum available for the study and to Amelia Knowlson for helping with the data collection at Dr Jenner's House Museum.

This research was conducted as part of the REVEAL project that received funding from the European Union's Horizon 2020 research and innovation programme under grant agreement No 732599.

\section{References}

Addison, A. C. 2000. Emerging Trends in Virtual Heritage. IEEE MultiMedia, April-June, 22-25.

Archeomatica 2016 Museo Glass Beacon: indagine sul gradimento della visita in realtá aumentata ai Mercati di Traiano https://www.archeomatica.it/musei/museo-glass-beacon-indaginegradimento-della-visita-realta-aumentata-mercati-di-traiano (accessed 7.2.2019)

Champion, E. 2015. Critical Gaming: Interactive History and Virtual Heritage. Ashgate.

Damala, A., Cubaud, P., Bationo, A., Houlier, P., and Marchal, I. 2008. Bridging the Gap between the Digital and the Physical: Design and Evaluation of a Mobile Augmented Reality Guide for the Museum Visit. Proc of. 3 ${ }^{\text {rd }}$ Int Conf on Digital Interactive Media in Entertainment and Arts DIMEA 2008, 120-127.

Dow, D. N. 2013. Historical Veneers: Anachronism, Simulation and Art History in Assassin's Creed II. In: Kapell, M.W. and Elliott, A. B. R. (eds.) Playing with the Past: Digital Games and Simulation of History. Bloomsbury, Lodon, 215-232.

Falk, H. J. and Dierking, L. D. 2000. Learning from Museums: Visitor Experiences and the Making of Meaning. Rowman \& Littlefield. Bond, N. and Falk, J. 2013. Tourism and identity-related motivations: why am I here (and not there)? Int. Journal of Tourism Research. 15, 430-442. DOI: $10.1002 /$ jtr.1886

Gaitatzes, A., Christopoulos, D., Roussou, M. 2001. Reviving the Past: Cultural Heritage Meets Virtual Reality. Proc of. the 2001 conference on Virtual reality, archeology, and cultural heritage VAST'01, 103-110.

Habgood, M.P.J., Wilson, D., Moore, D., Alapont, S. 2017. HCI Lessons From PlayStation VR. In Annual Symposium on Computer-Human Interaction in Play (CHI PLAY '17). ACM, New York, NY, USA, 125-135. DOI: https://doi.org/10.1145/3130859.3131437

Harringthon, M. 2012. The Virtual Trillium Trail and the empirical effects of Freedom and Fidelity on discovery-based learning. Virtual reality, 16 (2), 105-120.

Hornecker, E. 2010. Interactions around a contextually embedded system. In Proc. of the 4th Int. Conf. on Tangible, Embedded, and Embodied Interaction (TEI '10). ACM, New York, NY, USA, 169176. DOI: https://doi.org/10.1145/1709886.1709916

Jung, T., tom Dieck, M. C., Lee, H., Chung, N. 2016. Effects of Virtual Reality and Augmented Reality on visitor Experiences in Museum. In: Inversini, A. and Schegg, R. (eds.) Information and 
Communication Technology in Tourism, Springer International Publishing, Wien, New York, 621635 .

Kateros, S., Georgiou, S., Papaefthymiou, M., Papagiannakis, G., Tsioumas, M. 2015. A Comparison of Gamified, Immersive VR Curation Methods for Enhanced Presence and Human-computer Interaction in Digital Humanities. Int. Journal of Heritage in the Digital Era. 4 (2). 221- 233.

Kebele, M. K., Pierdicca, R., Frontoni, E., Savina Malinverni, E., Gain, J. 2018. A Survey of Augmente, Virtual, and Mixed Reality for Cultural Heritage. ACM Journal of Computing and Cultural Heritage. 11 (2), article 7.

Keil, J., Pujol, L., Roussou, M., Engelk, T., Schmitt, M., Eleftheratou, S. 2013. A digital look at physical museum exhibits - Designing personalized stories with handheld Augmented Reality in museums. Proc. of Digital Heritage International Congress, Marseille, France, IEEE Pub.

Liestøl, G. 2014. Along the Appian Way. Storytelling and Memory across Time and Space in Mobile Augmented Reality. In: M. Ioannides et al. (eds.): Proc. of EuroMed 2014, LNCS 8740, 248257.

Lowe, D. 2009. Playing with Antiquity: Videogame Receptions of the Classical World. In: Lowe, D. and Shahabudin, K. (eds.) Classics for All: Reworking Antiquity in Mass Culture. Cambridge Scholars Publishing. 62-88.

Malone, T. W. and Lepper, M. R. 1987. Making learning fun: A taxonomy of intrinsic motivations for learning. In: Snow, R. E. and Farr, M. J. (eds.). Aptitude, Learning and Instruction: III. Conative and affective process analyses. Hilsdale, NJ, Erlbaum, 223-253.

Marshall, M. T., Petrelli, D., Dulake, N., Not, E., Marchesoni, M., Trenti, E., Pisetti, A. 2016. Audiobased narratives for the trenches of World War I: Intertwining stories, places and interaction for an evocative experience. International journal of human-computer Studies - IJHCS, 85, January, 27-39.

Mason, M. 2016. The MIT Museum Glassware Prototype: Visitor Experience Exploration for Designing Smart Glasses. J. Comput. Cult. Herit. 9, 3, Article 12 (September 2016), 28 pages. DOI: https://doi-org.hallam.idm.oclc.org/10.1145/2872278

Milgram, P., Takemura, H., Utsumi, A., Kishino, F. 1994. Augmented Reality: A class of displays on the reality-virtuality continuum. SPIE Proc. Vol 2351, Telemanipulator and Telepresence Technologies, 282-292.

Museo della Scienza. 2018. Marte e Marziani. Museo della Scienza e della Tecnologia Leonardo da Vinci, Milano, Italy http://www.museoscienza.org/news/marte-e-marziani-2018/ (accessed 9.2.2019)

Pavid, K. 2018. Explore the Museum's collection with Sir David Attenborough. 6 March 2018 http://www.nhm.ac.uk/discover/news/2018/march/explore-the-museum-with-sir-davidattenborough.html (consulted January 28, 2019)

Petrelli, D. and O'Brien, S. 2018. Phone vs. Tangibles in Museum: A Comparative Study. Proc. of the 2018 CHI Conference on Human Factors in Computing Systems (CHI '18). ACM, New York, NY, USA, Paper 112, 12 pages. DOI: https://doi.org/10.1145/3173574.3173686

Pescarin, S. (ed.) 2014. Keys to Rome. Roman Culture, Virtual Museums. Edizioni CNR ITABC. DOI: $10.13140 / 2.1 .2631 .5046$

Poole, S. 2018. Ghosts in the Garden: locative gameplay and historical interpretation from below, Int. Journal of Heritage Studies, 24 (3), 300-314.

Pujol, L. 2004. Archaeology, Museums and Virtual Reality. Digitum, no. 6.

Rouse, R. 2010. Environmental Narrative: Your World is Your Story. In: San Francisco, Game Developers Conference, San Francisco: Game Developers Conference, .

Rae, J. and Edwards, L. 2016. Virtual reality at the British Museum: What is the value of virtual reality environments for learning by children and young people, schools, and families?. MW2016: Museums and the Web 2016. Published January 28, 2016. Consulted January 28, 2019.

https://mw2016.museumsandtheweb.com/paper/virtual-reality-at-the-british-museum-what- 
is-the-value-of-virtual-reality-environments-for-learning-by-children-and-young-peopleschools-and-families/

Schofield, J., Beale, G., Beale, N., Martin, F., Dawn, H., Hook, J., Murphy, D., Richards, J., and Thresh, L. 2018. Viking VR: Designing a Virtual Reality Experience for a Museum. Proc. of DIS Designing Interactive Systems 2018.

Shuemie, M., van der Straaten, P., Krijn, M, van der Mast, C. 2001. Research on Presence in Virtual Reality: A Survey. CyberPsychology \& Behavior, 4 (2). 183-201.

Soranzo, A., Petrelli, D., Ciolfi, L., Reidy, J. 2018. On the Perceptual Aesthetics of Interactive Objects. Quarterly Journal of Experimental Psychology. 71 (12). 2586-2602.

Stone, R., and Ojika, T. 2000 Virtual Heritage: What Next? IEEE MultiMedia, April-June, 73-74.

Tate Modern. 2017 Modigliani VR: The Ochre Atelier. https://www.tate.org.uk/whats-on/tatemodern/exhibition/modigliani/modigliani-vr-ochre-atelier (accessed 9.2.2019)

Whitaker, R. 2016. Backward Compatible: Gamers as a Public History Audience. Perspective on History. January. https://www.historians.org/publications-and-directories/perspectives-onhistory/january-2016/backward-compatible-gamers-as-a-public-history-audience (accessed 9.2.2019) 


\section{Appendix}

This appendix reports the Questionnaire and the Observation book as used in the study: page 1 and 2 of the questionnaire and the observation note were replicated for each of the device, while the final page of the questionnaire was unique and filled in only at the end of the visit.

PN:

Age: $<20 \quad 20-40 \quad 40-60 \quad 60>$

Group: family friends solo

Which device did you use?

Stereoscope

Tablet

How would you score your experience with it?

Pleasant

\begin{tabular}{|l|l|l|l|l|l|}
\hline Not at all & & & Indifferent & & \\
\hline
\end{tabular}

Special

\begin{tabular}{|l|l|l|l|l|l|l|}
\hline Not at all & & & Indifferent & & & Very much \\
\hline
\end{tabular}

Comfortable

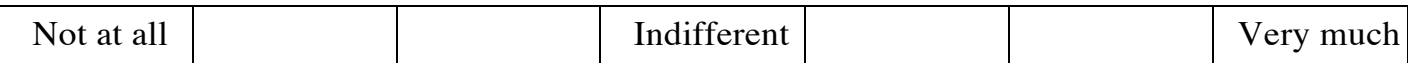

\section{Interesting}

\begin{tabular}{|c|c|c|}
\hline & In \\
\hline
\end{tabular}

\section{Surprising}

\begin{tabular}{|l|l|l|l|l|l|}
\hline Not at all & & & Indifferent & & \\
\hline
\end{tabular}

\section{Useful}

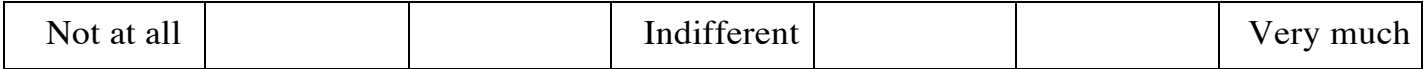

\section{Playful}

\begin{tabular}{|l|l|l|l|l|l|l|}
\hline Not at all & & & Indifferent & & & Very much \\
\hline
\end{tabular}

\section{Easy to use}

\begin{tabular}{|l|l|l|l|l|l|}
\hline Not at all & & & Indifferent & & \\
Very much
\end{tabular}

\section{Relaxing}

\begin{tabular}{|c|c|c|}
\hline Not at all & Indifferent & Very much \\
\hline
\end{tabular}


How much do you agree with the following statements?

I felt like I stepped back in time

\begin{tabular}{|l|l|l|l|l|l|}
\hline Not at all & & Indifferent & & & Very much \\
\hline
\end{tabular}

I felt involved

\begin{tabular}{|l|l|l|l|l|l|l|}
\hline Not at all & & & Indifferent & & & Very much \\
\hline
\end{tabular}

It was interesting to see how the house has changed from the early $19^{\text {th }}$ century

\begin{tabular}{|l|l|l|l|l|l|l|}
\hline Not at all & & Indifferent & & & Very much \\
\hline
\end{tabular}

Finding and playing the stories was fun

\begin{tabular}{|l|l|l|l|l|l|l|}
\hline Not at all & & Indifferent & & & Very much \\
\hline
\end{tabular}

The stories were interesting

\begin{tabular}{|l|l|l|l|l|l|l|}
\hline Not at all & & & Indifferent & & & Very much \\
\hline
\end{tabular}

I felt isolated

\begin{tabular}{|l|l|l|l|l|l|}
\hline Not at all & & Indifferent & & & Very much \\
\hline
\end{tabular}

It was difficult to share the experience with my companions

\begin{tabular}{|l|l|l|l|l|l|l|}
\hline Not at all & & & Indifferent & & & Very much \\
\hline
\end{tabular}

How would you describe this experience to someone who has not used this before?

>>> please return the questionnaire to the researcher. 


\section{Observer's Notes}

Group: family-small-children [ ] family-teens [ ] teens [ ] mature[ ] elderly [ ]
Which floor are they?
ground-floor
first-floor
garden

How do they move?

Do they share? How?

Behaviour when using the device: 
Please spend a few moments thinking of your overall experience and tell us:

Which interaction did you like the best?

Why?

Why?

Is there anything more you want to say to us? Anything at all? 